\title{
Overview of Advanced Reactor Simulation Capabilities to Support Demonstrations
}

\section{JUNE 2021}

Virtual Test Bed (VTB)

Abdalla Abou-Jaoude, Guillaume Giudicelli, Derek Gaston, Paolo Balestra, Nicolas Martin, and Cody Permann Idaho National Laboratory

Bo Feng, Jun Fang, April Novak, Nicolas Stauff, Thanh Hua, Dillon Shaver, and Ling Zou

Argonne National Laboratory 


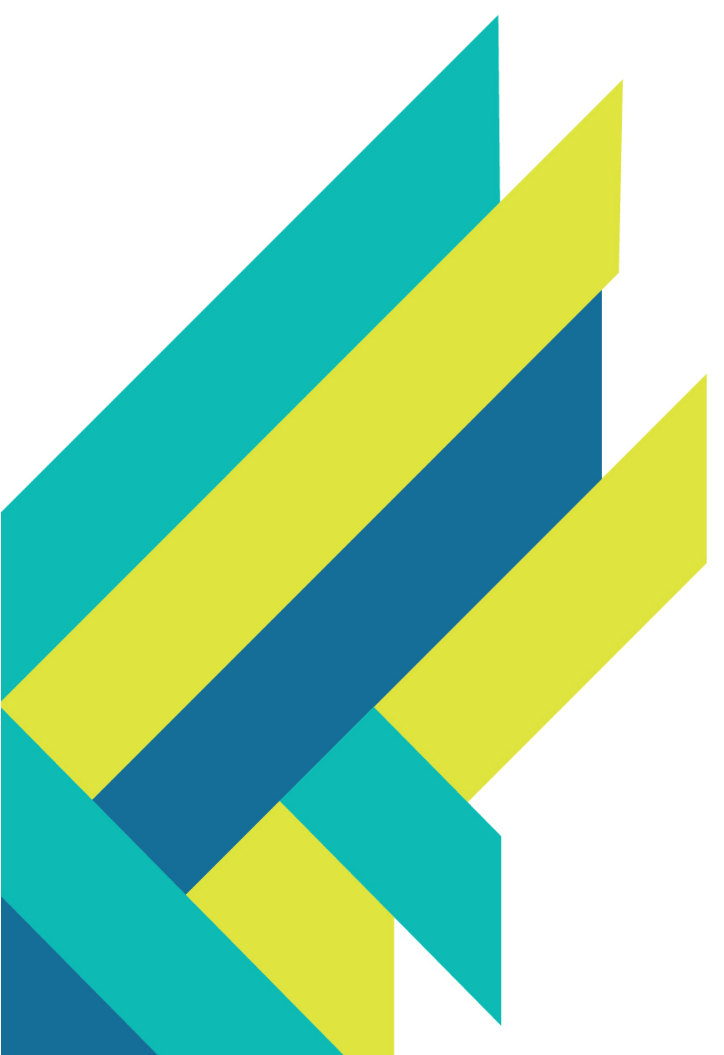

\section{DISCLAIMER}

This information was prepared as an account of work sponsored by an agency of the U.S.

Government. Neither the U.S. Government nor any agency thereof, nor any of their employees, makes any warranty, expressed or implied, or assumes any legal liability or responsibility for the accuracy, completeness, or usefulness, of any information, apparatus, product, or process disclosed, or represents that its use would not infringe privately owned rights. References herein to any specific commercial product, process, or service by trade name, trade mark, manufacturer, or otherwise, does not necessarily constitute or imply its endorsement, recommendation, or favoring by the U.S. Government or any agency thereof. The views and opinions of authors expressed herein do not necessarily state or reflect those of the U.S. Government or any agency thereof.

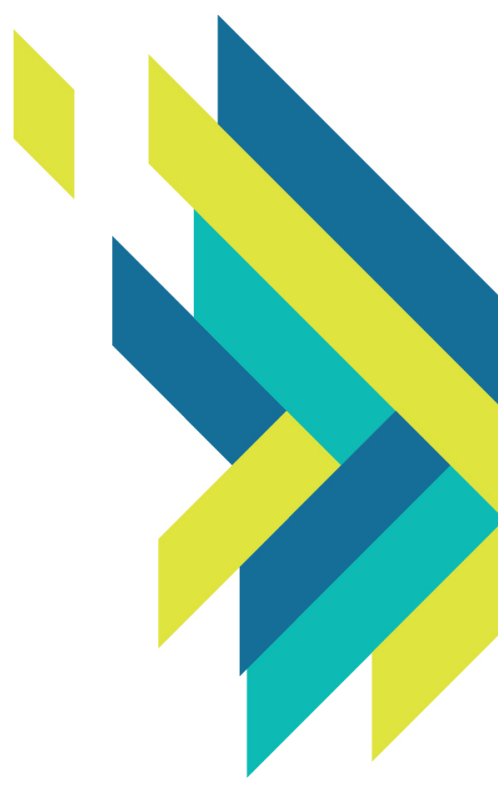




\section{REVISION LOG}

\begin{tabular}{|l|l|l|l|}
\hline $\begin{array}{c}\text { Revision } \\
\text { No. }\end{array}$ & Date & Affected Pages & \multicolumn{1}{|c|}{ Description } \\
\hline 0 & $06 / 11 / 2021$ & All & New Document \\
\hline & & & \\
\hline & & & \\
\hline & & & \\
\hline
\end{tabular}


Page intentionally left blank 


\section{SUMMARY}

The Virtual Test Bed (VTB) was established to support the deployment of advanced reactors by facilitating the use of state-of-the-art modeling and simulation capabilities. These tools are able to solve previously prohibitive challenge problems in greater levels of fidelity and in a multiphysics framework. A VTB repository was recently set up to host models for a wide variety of reactor types and using a range of Nuclear Energy Advanced Modeling and Simulation-developed software. Table I summarizes the different capabilities already available in the repository and up and coming: near and long term. The repository currently hosts models for a variety of reactor types, including High-Temperature GasCooled Reactors, Sodium Fast Reactors, Fluoride-salt-cooled Hightemperature Reactors, Molten Salt Reactors, and Heat-Pipe Microreactors. It should be noted that work is ongoing for all of the models and each example problem is at a different state of maturity. More information on each case can be found in their corresponding documentation.

Table I. Status of models in the VTB repository based on examples being available, coming in near/long-term (near, long), not applicable (N/A), and not under current development (unplanned). Note that the level of maturity of models can vary greatly between each case.

\begin{tabular}{|l|c|c|c|c|c|c|}
\hline & Griffin & Pronghorn & SAM & Nek & Sockeye & BISON \\
\hline HTGR & Available & Available & Available & Long & N/A & Near \\
\hline SFR & Available & Long & Available & Long & N/A & Available \\
\hline HP-MR & Near & N/A & Near & Unplanned & Available & Available \\
\hline FHR & Available & Near & Available & Available & N/A & Near \\
\hline MSR & Available & Near & Near & Available & N/A & N/A \\
\hline GFR & Unplanned & Unplanned & Unplanned & Unplanned & N/A & Unplanned \\
\hline
\end{tabular}


Page intentionally left blank 


\section{CONTENTS}

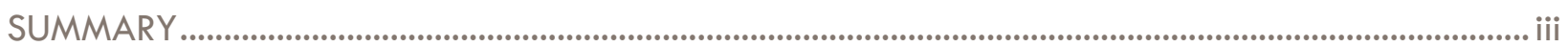

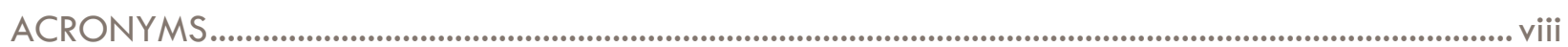

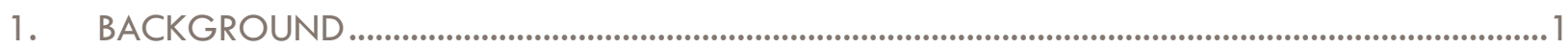

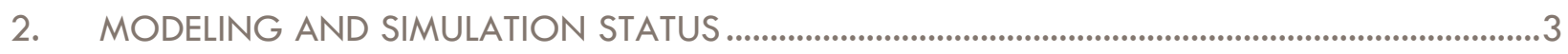

2.1 High-Temperature Gas-cooled Reactors (HTGR) ......................................................................4

2.1.1 Current Capabilities ................................................................................................................4

2.1.2 Near- and Long-Term Capabilities............................................................................5

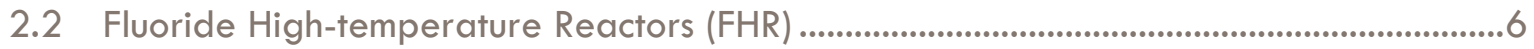

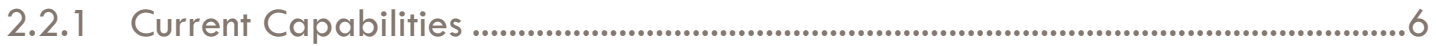

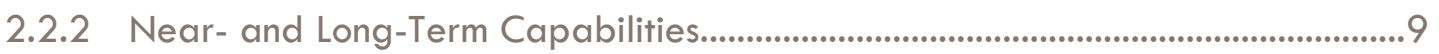

2.3 Molten Salt Reactors (MSR) .......................................................................................................

2.3.1 Current Capabilities .......................................................................................................... 10

2.3.2 Near- and Long-Term Capabilities.............................................................................. 11

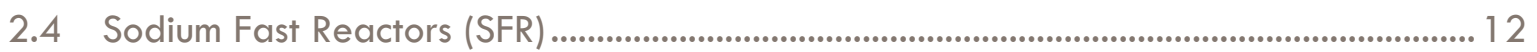

2.4.1 Current Capabilities ................................................................................................ 12

2.4.2 Near- and Long-Term Capabilities...................................................................... 14

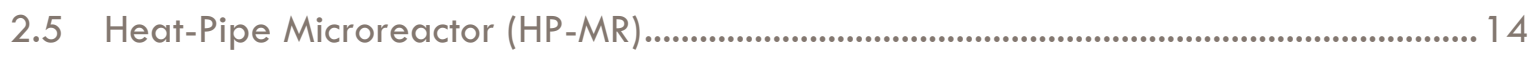

2.5.1 Current Capabilities .............................................................................................. 15

2.5.2 Near- and Long-Term Capabilities............................................................................ 17

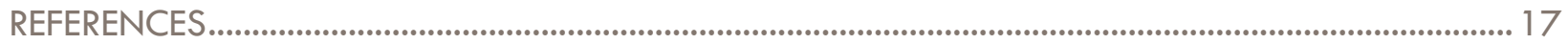

\section{FIGURES}

Figure 1. Breakdown of the ARDP applicants and awardees by reactor type........................... 2

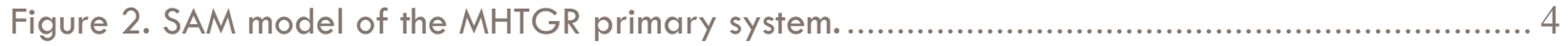

Figure 3. Coupled Griffin+Pronghorn simulation of the PBMR-400....................................... 5

Figure 4. FHR Griffin+Pronghorn coupling scheme........................................................... 7

Figure 5. Coupled Griffin+Pronghorn results for the Mk-1 FHR concept................................... 7

Figure 6. Nek-RS simulation of an FHR reflector/bypass flow............................................. 8

Figure 7. Fluid system temperature distribution inside the FHR balance of plant........................ 9

Figure 8. Coupled Griffin+Pronghorn simulation of the MSFR............................................. 10

Figure 9. Illustration of the recently implemented MSR delayed neutron drifting effect

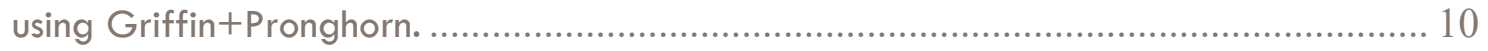

Figure 10. High-fidelity Nek-5000 simulation of the MSFR core ........................................... 11 


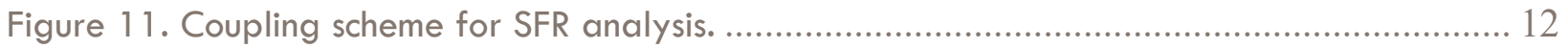

Figure 12. Different meshes used in each code block of the SFR lattice example....................... 13

Figure 13. Power density and axial displacement magnitude.................................................... 14

Figure 14. Coupled Griffin+Pronghorn results for the HP-MR analysis ................................... 15

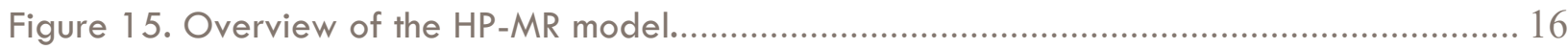

Figure 16. Results from the multiphysics simulation of the HP-MR. Temperature values are

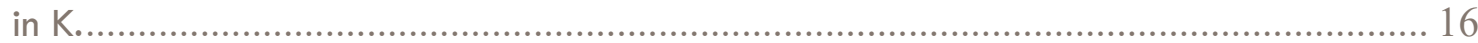

\section{TABLES}

Table I. Status of models in the VTB repository based on examples being available, coming in near/long-term (near, long), not applicable (N/A), and not under current development (unplanned). Note that the level of maturity of models can vary greatly between each case.

Table II. Overview of VTB M\&S status and gaps for advanced reactor types. 


\section{Page intentionally left blank}




\section{ACRONYMS}

INL Idaho National Laboratory

NRIC National Reactor Innovation Center

VTB Virtual Test Bed

DOE Department of Energy

NEAMS Nuclear Energy Advanced Modeling and Simulations

ART Advanced Reactor Technology

NRC Nuclear Regulatory Commission

HTGR High-Temperature Gas Reactor

SFR Sodium Fast Reactor

MSR Molten Salt Reactor

FHR Fluoride High-temperature Reactor

HP-MR Heat-Pipe Microreactor

GC-MR Gas-Cooled Microreactor

PWR Pressurized Water Reactor

BWR Boiling Water Reactor

M\&S Modeling \& Simulations 


\section{Page intentionally left blank}




\section{Overview of Advanced Reactor Simulation Capabilities to Support Demonstrations}

\section{BACKGROUND}

Following the passage of the Nuclear Energy Innovation Capabilities Act, the National Reactor Innovation Center (NRIC) was created for accelerating the deployment of these novel reactor concepts. This will be achieved by providing both physical and virtual spaces for building and testing various components, systems, and complete pilot plants. The Virtual Test Bed (VTB) represents the virtual arm. It is being developed in collaboration with Department of Energy's (DOE) Nuclear Energy Advanced Modeling and Simulation (NEAMS) program.

The mission of the VTB is to accelerate the deployment of advanced reactors by facilitating the adoption of advanced modeling and simulation (M\&S) tools developed by the DOE NEAMS programs. This is achieved by two primary means: (1) storing example challenge problems in an externally available repository, and (2) developing models to fill the M\&S gaps needed by industry.

This report primarily provides an overview of simulation capabilities being developed to support advanced reactor demonstrations (Item 2). This includes work sponsored directly by NRIC, as well as by other NE-5 programs (namely NEAMS and Advanced Reactor Technologies [ART]). A wide range of these models are being hosted in an online, open-source repository to exhibit "challenge problems" that are relevant to potential reactor demonstrations. The report will highlight the status of NEAMS-based M\&S advanced reactor models that are hosted and provide some guidelines on expected priorities for the short and long term. The intent for this report is to showcase advanced reactor M\&S capabilities to external stakeholders. The report is expected to be updated on a yearly basis as new simulation capabilities become available.

The VTB intends to prioritize hosting models that are of interest to potential reactor demonstration efforts. As such, the models highlighted in this report follow the recommendations of an internally conducted industry review. a Figure 1 shows the breakdown by reactor type of applicants and awardees to the Advanced Reactor Demonstration Program (ARDP). The awardees include all three tiers: demonstration, risk reduction, and advanced reactor concepts awards. It is interesting to note that awards were nearly evenly split between each reactor type, with Sodium Fast Reactors (SFR) and High-Temperature Gas Reactors (HTGR) receiving slightly more awards. The application pool distribution was even more widespread, with a broader range of reactor types. Molten Salt Reactors (MSR) and Gas-Cooled Microreactors (GC-MR) applicants were slightly more common than others at this stage. Other concepts being pursued by reactor demonstrators include Fluoride High-temperature Reactors (FHRs), Heat-Pipe Microreactors (HPMR), and Gas Fast Reactors (GFRs), as well as more traditional Pressurized and Boiling Water Reactors (PWRs and BWRs).

a NRIC VTB RC-20IN020602 Milestone Report, February 2021. 
ARDP Applicant by Reactor Types

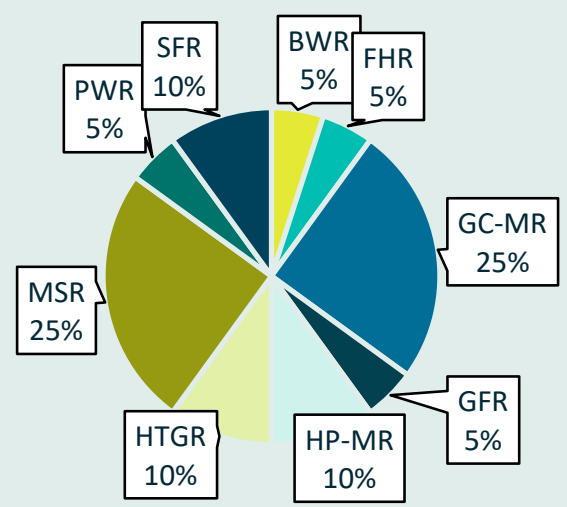

ARDP Awards by Reactor Type

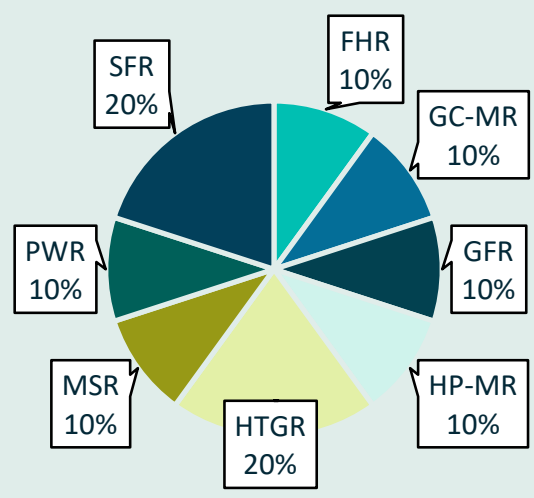

Figure 1. Breakdown of the ARDP applicants and awardees by reactor type.

The primary emphasis on the application of NEAMS tools is to non-light-water concepts. Table II provides an overview of the M\&S status for advanced reactor concepts. The most mature capabilities are in the HTGR space, with SFR and HP-MR closely behind. FHR and MSR models were less advanced; therefore, these models have been supported by the VTB program. Current capabilities for GFR and GC-MR are more limited, but a lot of the existing work on other similar reactor types (namely for HTGR) may be leveraged.

Table II. Overview of VTB M\&S status and gaps for advanced reactor types. Initial emphasis is placed on neutronic and thermal aspects, with fuel performance and chemistry to be investigated closer in the future.

\begin{tabular}{|c|c|c|c|}
\hline Reactor Type & Demonstration Interest & M\&S Status in VTB & Some Highlighted Gap \\
\hline HTGR-pebble & $\begin{array}{l}\text { Strong interest with one ARDP } \\
\text { demonstration award }\end{array}$ & $\begin{array}{l}\text { Example multiphysics models } \\
\text { developed, including } \\
\text { benchmarks }\end{array}$ & $\begin{array}{l}\text { Pebble depletion tracking, } \\
\text { multiphysics transients with } \\
\text { balance of plant model }\end{array}$ \\
\hline $\begin{array}{l}\text { HTGR-prismatic } \\
\text { (+GC-MR) }\end{array}$ & $\begin{array}{l}\text { Strong interest with one ARDP } \\
\text { risk reduction, and one } \\
\text { advanced concept award }\end{array}$ & $\begin{array}{l}\text { System code transient models } \\
\text { developed }\end{array}$ & $\begin{array}{l}\text { High-fidelity multiphysics transient } \\
\text { models both for small modular } \\
\text { reactors and microreactor variants }\end{array}$ \\
\hline SFR & $\begin{array}{l}\text { Strong interest with multiple } \\
\text { ARDP awards }\end{array}$ & $\begin{array}{l}\text { Example multiphysics models } \\
\text { developed }\end{array}$ & $\begin{array}{l}\text { High-fidelity multiphysics transient } \\
\text { model (e.g., core bowing effect) }\end{array}$ \\
\hline HP-MR & $\begin{array}{l}\text { Strong interest with } \\
\text { ARDP/Department of Defense } \\
\text { awards }\end{array}$ & $\begin{array}{l}\text { Example multiphysics models } \\
\text { developed }\end{array}$ & $\begin{array}{l}\text { Full-core neutronics, transient } \\
\text { heat-pipe simulations }\end{array}$ \\
\hline FHR & ARDP risk reduction award & $\begin{array}{l}\text { Initial multiphysics models, } \\
\text { coolant system model, initial } \\
\text { bypass computational fluid } \\
\text { dynamics (CFD) }\end{array}$ & $\begin{array}{l}\text { Multiphysics transient model, } \\
\text { fluid-structure interaction, bypass } \\
\text { flow, fuel performance }\end{array}$ \\
\hline MSR & $\begin{array}{l}\text { Strong industry interest with } \\
\text { one ARDP risk reduction } \\
\text { award }\end{array}$ & $\begin{array}{l}\text { Initial multiphysics transient } \\
\text { models, initial high-fidelity CFD }\end{array}$ & $\begin{array}{l}\text { Multiphysics transient model, } \\
\text { structural feedback, coolant } \\
\text { system model, species tracking }\end{array}$ \\
\hline
\end{tabular}


GFR

One ARDP advanced concept award
No existing models but can

leverage SFR/HTGR work
Initial multiphysics model with transient capability

\section{MODELING AND SIMULATION STATUS}

The main objective of this report is to provide an overview of the M\&S status of advanced reactors to inform key stakeholders of existing and upcoming capabilities. A summary of key capabilities uploaded to the VTB repository are provided in this section. Note that this is not intended to be comprehensive, with multiple disparate ongoing research projects developing novel capabilities for each reactor types within the DOE complex and in academia. Additional information on the NEAMS tools can be found on the website: https://inl.gov/neams. The intent of this report is to primarily highlight M\&S capabilities identified by the authors and incorporated into the VTB repository. Some of the ongoing work is briefly touched upon as near-and long-term upcoming capabilities in each subsection. The section is grouped between HTGRs, FHR, MSR, SFRs, and HP-MR. Different simulation conditions are provided for each reactor type.

A range of NEAMS code are being showcased in the VTB repository as well. A brief summary of the main tools is provided below:

- MOOSE: MOOSE is the underlying framework for most of the NEAMS physics tools as well as the capability for connecting multiple physics applications together. It is a simulation framework that aids in application development by harnessing state-of-the-art fully coupled, fully implicit multiphysics solvers while providing automatic parallelization, mesh adaptivity, simplified application coupling and a growing set of physics modules [1].

- Griffin: Griffin is specially designed to support multiphysics applications and to natively couple to any MOOSE application. It is a time-dependent reactor physics code built using the MOOSE framework with weak form formulations for diffusion, $P_{N}$, and first- and second-order $S_{N}$ transport and a variety of equivalence techniques with acceleration [2], [3].

- Pronghorn: Pronghorn is a multidimensional, coarse-mesh, thermal-hydraulics (TH) code for advanced reactors. It serves the intermediate fidelity realm situated between detailed computational fluid dynamics (CFD) analysis and lumped system models. Application development has focused on gas-cooled pebble bed (PBR) and prismatic reactors, FHRs, and open-pool molten salt reactors (MSRs) [4], [5].

- SAM: SAM is a fast-running, whole-plant transient analysis code with improved-fidelity capability for fast turnaround design scoping and safety analyses of advanced non-lightwater reactors. The system code capabilities include 1-D flow and multichannel representations of reactor coolant systems, point kinetics models, specific component models, mass transport capability for species transport, control and trip system models, as well as reduced-order multidimensional models [6].

- Nek: Nek5000 is a high-fidelity CFD code based on the spectral element method. It can simulate fluid flows and heat transfer at high spatial discretization order using a variety of turbulence models including direct numerical simulation, large eddy simulation, and Reynoldsaveraged Navier-Stokes (RANS). It has demonstrated impressive computational scalability, routinely running on leadership class high-performance computing (HPC) facilities [7].

- BISON: Built on top of MOOSE, which solves partial differential equations important to fuel performance via finite element (energy conservation, stress divergence, and species migration), BISON adds specific fuel behavior and material models designed to represent the 
response of fuel and cladding/structural layers in a variety of reactor types. The code has been applied to $\mathrm{UO}_{2}$, TRISO, metallic, $\mathrm{UN} / \mathrm{UC}$, and $\mathrm{U}_{3} \mathrm{Si}_{2}$ fuel performance prediction [8].

- Sockeye: Sockeye is a MOOSE-based heat-pipe simulator and analysis tool. Heat-pipe simulation offers the ability to accurately predict heat transfer for applications involving heat pipes, including heat-pipe-cooled microreactors. Additionally, it provides insight on heat-pipe performance; operational heat-pipe limits can be predicted in transient conditions and with greater flexibility than steady-state analyses can provide [9].

\subsection{High-Temperature Gas-cooled Reactors (HTGR)}

HTGR are relatively mature advanced reactor concepts, with multiple plants having operated in the past. There exists a wide variety of different HTGR concepts, but generally they rely on TRISO-based fuel forms, contained within a matrix (typically graphite), and cooled by a hightemperature gas (typically helium). The main two sub-categories of HTGR are prismatic (the fuel particles are contained within blocks), and pebble bed (with the particles contained within a pebble circulating through the core). Examples of each are provided in the VTB repository.

\subsubsection{Current Capabilities}

A reactor core and primary system model of the prismatic design using SAM is included. The model is based on the General Atomic's 600-MWt Modular High-Temperature Gas-Cooled Reactor (MHTGR) [10]. The core model was developed using a ring approach based on a specified coolant channel pitch of fuel assembly [1 1][12]. All components including fuel, reflectors, coolant channels, core barrel, reactor pressure vessel, and reactor cavity cooling system are modeled as concentric cylindrical rings. The active core consists of three fuel rings: inner, middle, and outer ring. Each fuel ring is represented by 11 coolant channels and 22 heat structures. Thus, the active core is simulated using 99 circular rings with 66 rings for homogenized fuel heat structure and 33 rings for gas coolant. Each coolant ring is sandwiched between two heat structure rings. The two surfaces of these two heat structure rings that form the walls of the coolant ring are thermally equilibrated via surface coupling to prevent unphysical temperature discontinuity. Figure 2 shows the coolant temperature profile during normal operation.
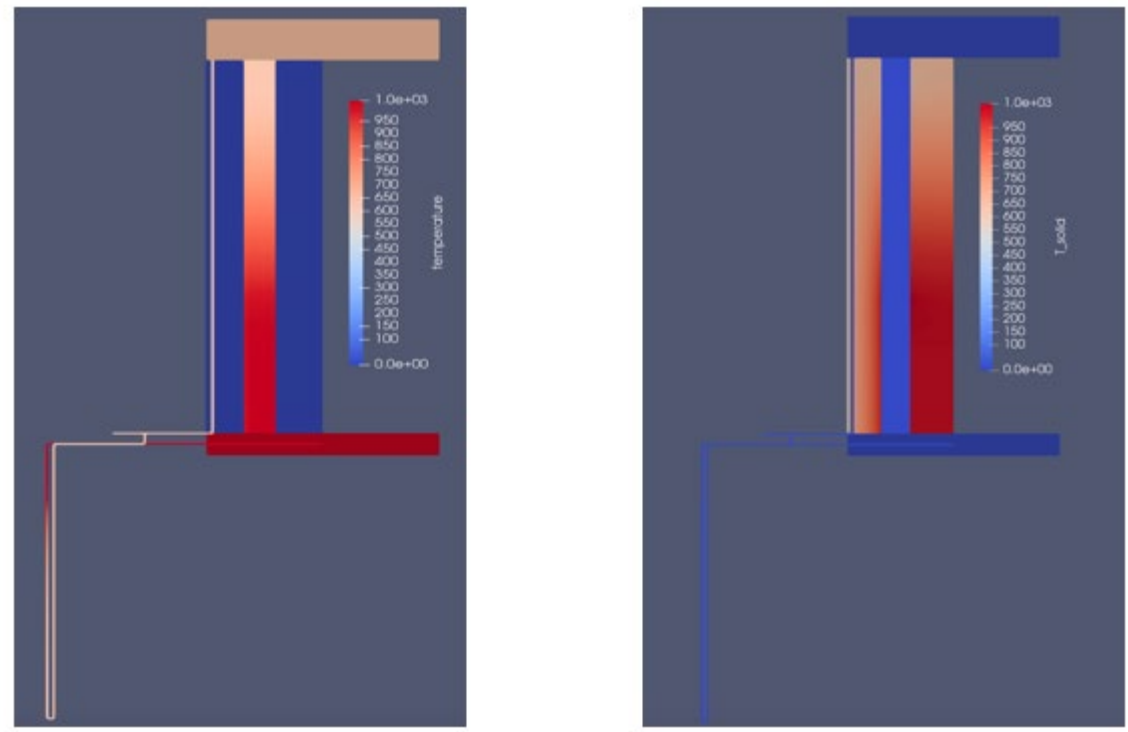

Figure 2. SAM model of the MHTGR primary system. 
The pebble-bed-based example in the VTB repository leverages the 400-MW Pebble Bed Modular Reactor (PBMR-400) demonstration power plant benchmark [13]. It is a modular thermal reactor moderated with graphite and cooled with helium. The $9.6 \%$ uranium dioxide fuel is encapsulated by different shells of pyrolytic graphite and ceramic material called TRISO particle. During normal operation, $192.7 \mathrm{~kg} / \mathrm{s}$ of helium at an inlet temperature of $773 \mathrm{~K}$ flows through the pebbles from top to bottom, reaching roughly $1173 \mathrm{~K}$ at the outlet. Additional information on the use case is provided in the repository documentation.

The two-dimensional flux and power density profiles are computed by Griffin, while the helium pressure, temperature, and velocity streamlines are computed by Pronghorn. The results of the steady-state analysis are shown in Figure 3. The spatial temperature distribution shows a temperature peak of $\sim 1,300 \mathrm{~K}$ close to the bottom center of the core.

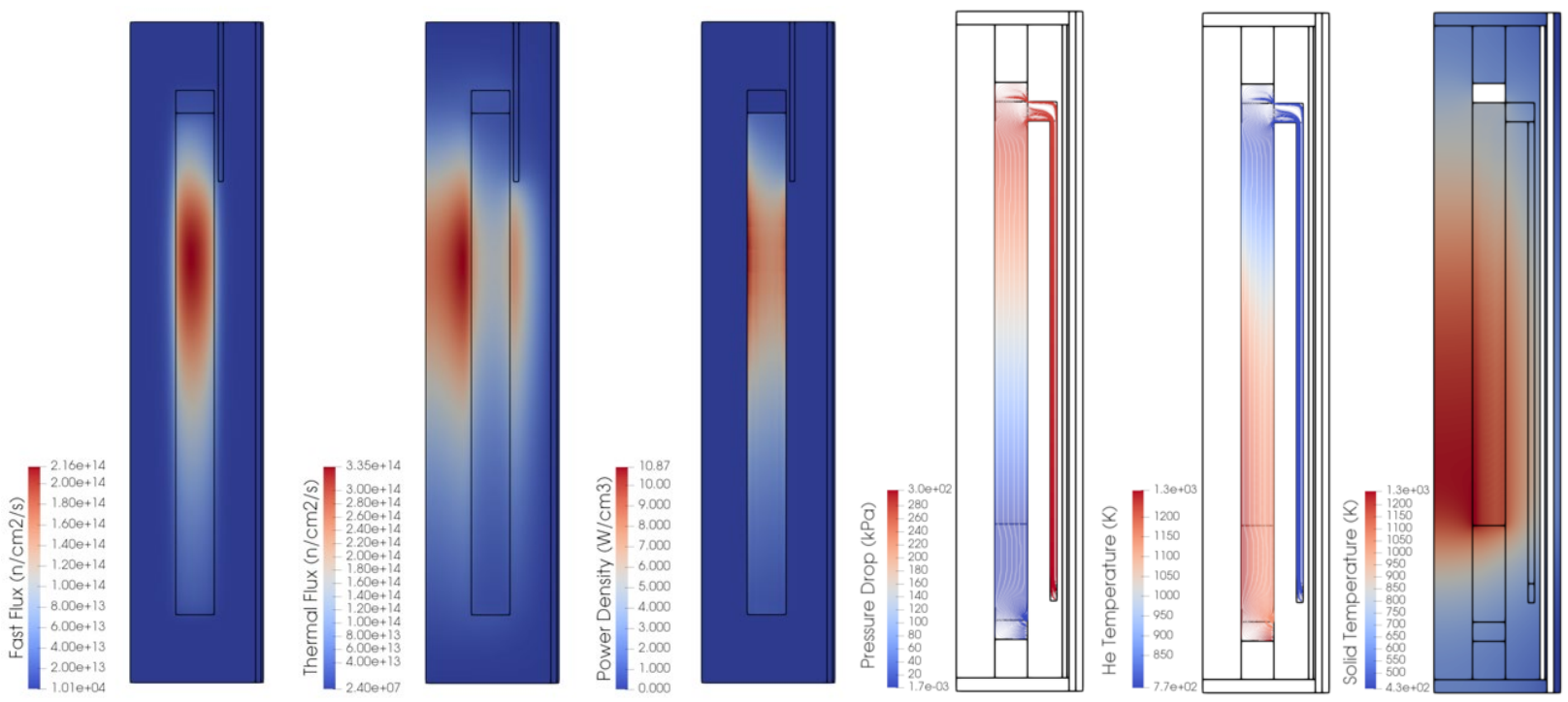

Figure 3. Coupled Griffin+Pronghorn simulation of the PBMR-400.

In addition to the steady-state calculations, a pressurized loss of forced cooling (PLOFC) example is uploaded to the repository. It simulates the sequence of events below:

- 0-13 s: A reduction in reactor inlet coolant mass flow from nominal to $0.0 \mathrm{~kg} / \mathrm{s}$. The mass flow ramp is assumed linear. A reduction in reactor helium outlet pressure from nominal 90 bar to 60 bar.

- 13-16 s: All control rods are fully inserted over $3 \mathrm{~s}$ to SCRAM the reactor.

- 16-180,000 s: No change in input parameters (50 h).

\subsubsection{Near- and Long-Term Capabilities}

Multiple ongoing efforts intend to augment HTGR M\&S capabilities using NEAMS tools. The list below is not expected to be comprehensive but rather highlight the capabilities that the VTB team has been actively coordinating with the corresponding groups to bring to the repository. The efforts are grouped within near term (currently under development and expected to become available within a year), and longer-term ones (on the capability "wish list" but no formal plans have been made to develop the capability). 
- Near Term:

- Benchmarks and validation examples of NEAMS codes against gas-cooled experiments and operational HTGRs

- Pebble depletion tracking capability as pebbles are cycled through the core

- High-fidelity computing of a pebble bed core using HPC capabilities (Cardinal tool)

- System-level analysis capability of pebble bed HTGR using SAM for both steady-state and transient conditions.

- Long Term:

- TRISO fuel performance modeling with BISON coupled to Griffin, Pronghorn, and SAM capabilities

- Development of a horizontal GC-MR model to simulate relevant transients to this HTGRsubclass.

\subsection{Fluoride High-temperature Reactors (FHR)}

FHRs are a novel class of reactors that merge attractive features from other reactor types. They typically rely on TRISO-based fuel forms contained in pebbles, plates, or blocks, but contrary to HTGRs, are cooled by molten salt at atmospheric pressure (typically FLiBe). The opensource Mk1 PB-FHR model developed by UC Berkeley ${ }^{b}$ has been primarily leveraged in the VTB. The concept uses an air Brayton cycle to produce $100 \mathrm{MWe}$ from $236 \mathrm{MW}$ th, with the possibility of natural gas co-firing for additional power output. The Mkl design has an annular cylindrical core. The salt flows upwards and pebbles are buoyant and float at the top of the core. Pebbles enter through a fueling chute, while the fluoride-salt coolant flows from both the fueling chute and the inner reflector. Pebbles leave the core through a defueling chute at the top of the core. Coupled Griffin+Pronghorn models were developed to simulate behavior within the core, Nek was leveraged to study the bypass flow inside the reflector, and SAM was used for analysis of the primary system excluding the reactor core.

\subsubsection{Current Capabilities}

Griffin+Pronghorn coupled simulations are included in the VTB in both steady-state and transient simulations. The coupling scheme codes between the codes highlighted in Figure 4. Serpent was externally used to generate nuclear cross-sectional data for the simulation, while the heat conduction was treated internally within MOOSE.

b Refer to: https://fhr.nuc.berkeley.edu/ 


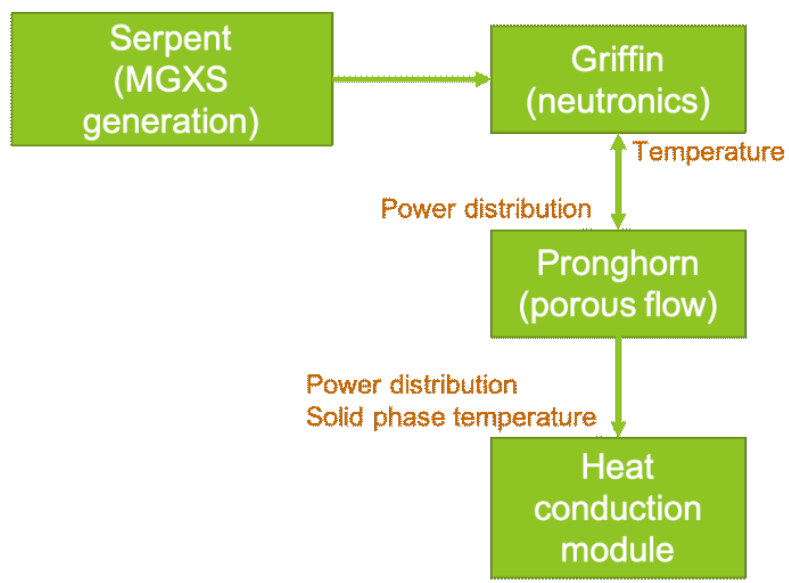

Figure 4. FHR Griffin+Pronghorn coupling scheme.

The two-dimensional flux and power densities are computed by Griffin, which passes heat generation values to Pronghorn that is used to estimate reactor temperature distributions. Heat conduction models leveraged in the HTGR analysis were repurposed here to estimate temperature distribution within the pebbles and within TRISO particles. This allows the simulation to approximate the average and maximum solid and fluid phase temperatures as illustrated in Figure 5.

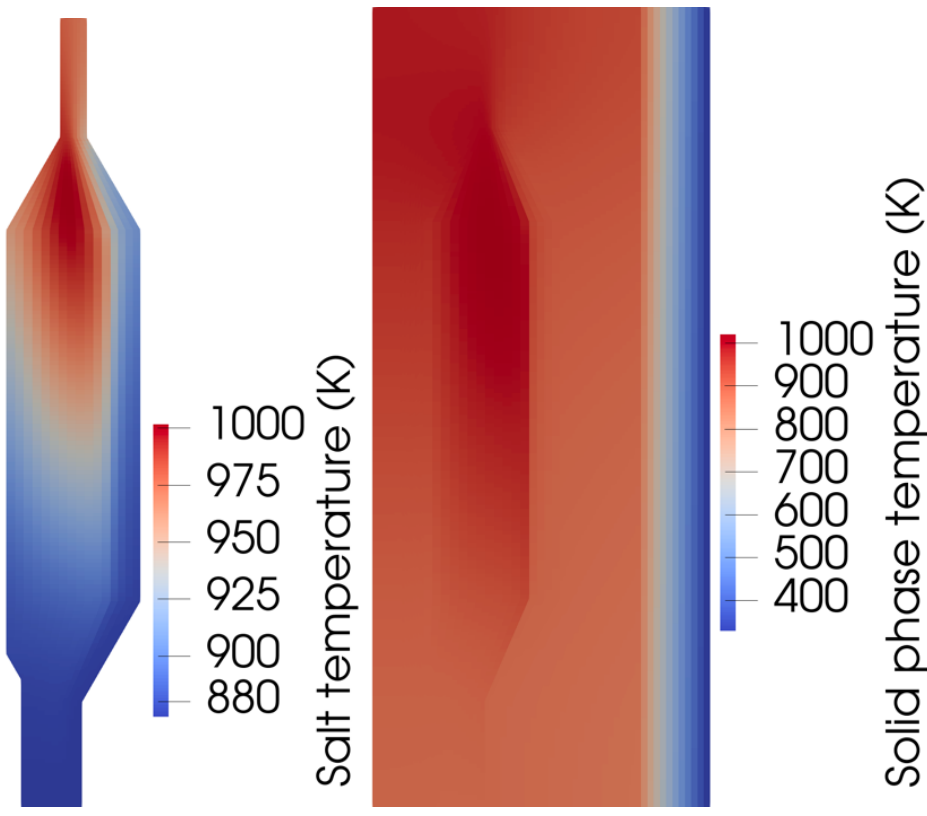

Figure 5. Coupled Griffin+Pronghorn results for the Mk-1 FHR concept.

An example transient FHR simulation was also included in the VTB repository. It consists of a control rod ejection accident. The central bank is moved linearly from half inserted to $3 / 8^{\text {th }}$ inserted for $1 \mathrm{~s}$, then the rods are fully reinserted to simulate a scram. The power exponentially increases over a few tenths of a second, and the fuel temperature follows the same trend. The reactivity spike is eventually reduced by the Doppler effect in the fuel. 
Nek CFD simulations of FHR systems were also included in the VTB repository. The primary focus was on modeling the bypass flow within the external radial reflector. To keep the graphite reflector within allowable design temperatures, the reflector contains several bypass flows paths so that a small percentage of the coolant flow can maintain adequate temperatures. It is important to adequately capture behaviors within that region when trying to predict reflector temperatures during a range of conditions. The resulting pressure between the blocks is shown in Figure 6. The analysis can provide the foundation for developing bypass flow closure relations that would be leveraged in Pronghorn.

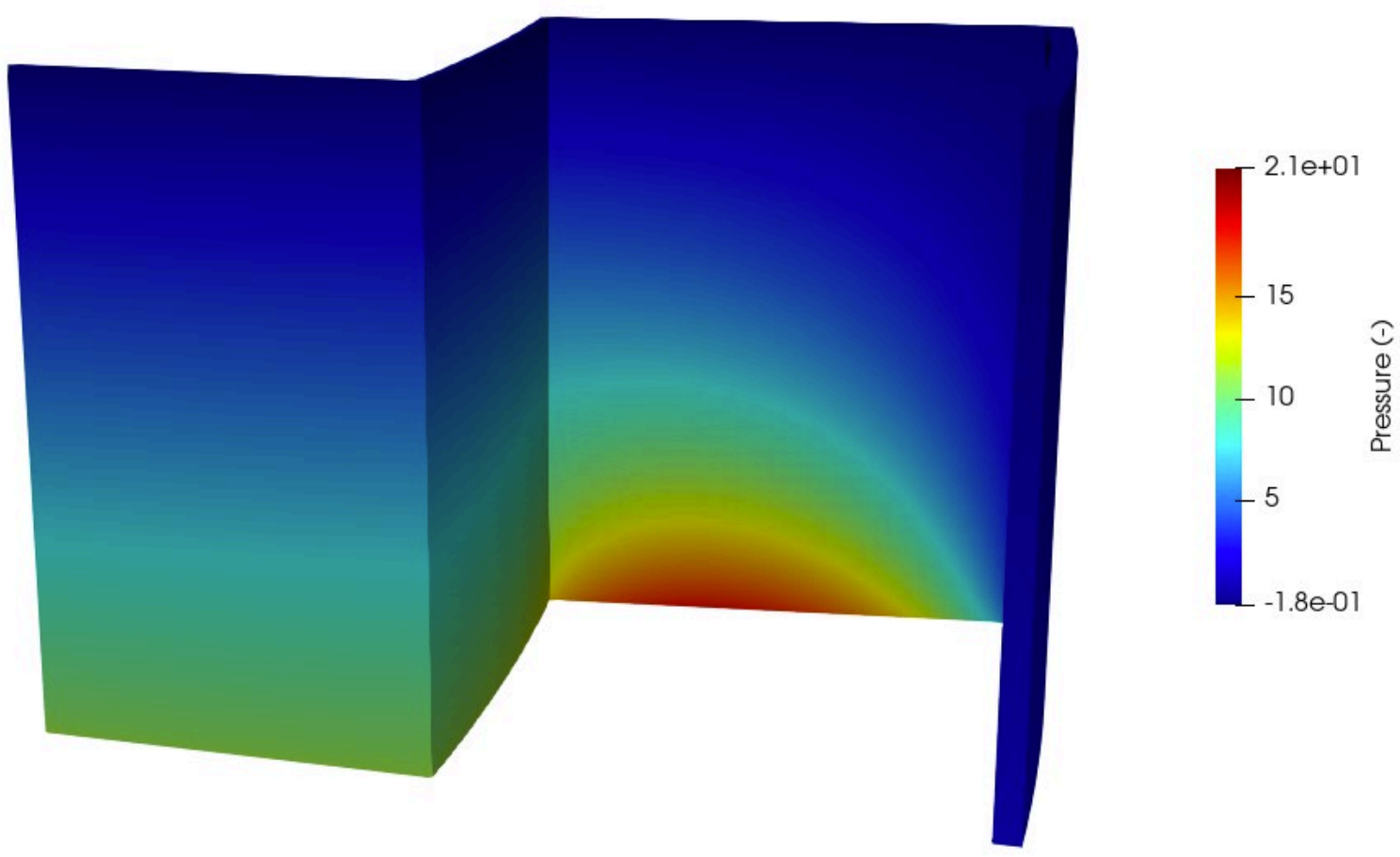

Figure 6. Nek-RS simulation of an FHR reflector/bypass flow.

Lastly, a 1-D SAM model of the FHR primary system was showcased in the repository. The model here is based on the $M k 1$ concept with slight component modifications at the system level. The simulation includes a simplified model for the core and accounts for the different components within the primarily loop. A transient simulation example was generated to demonstrate the capability. 


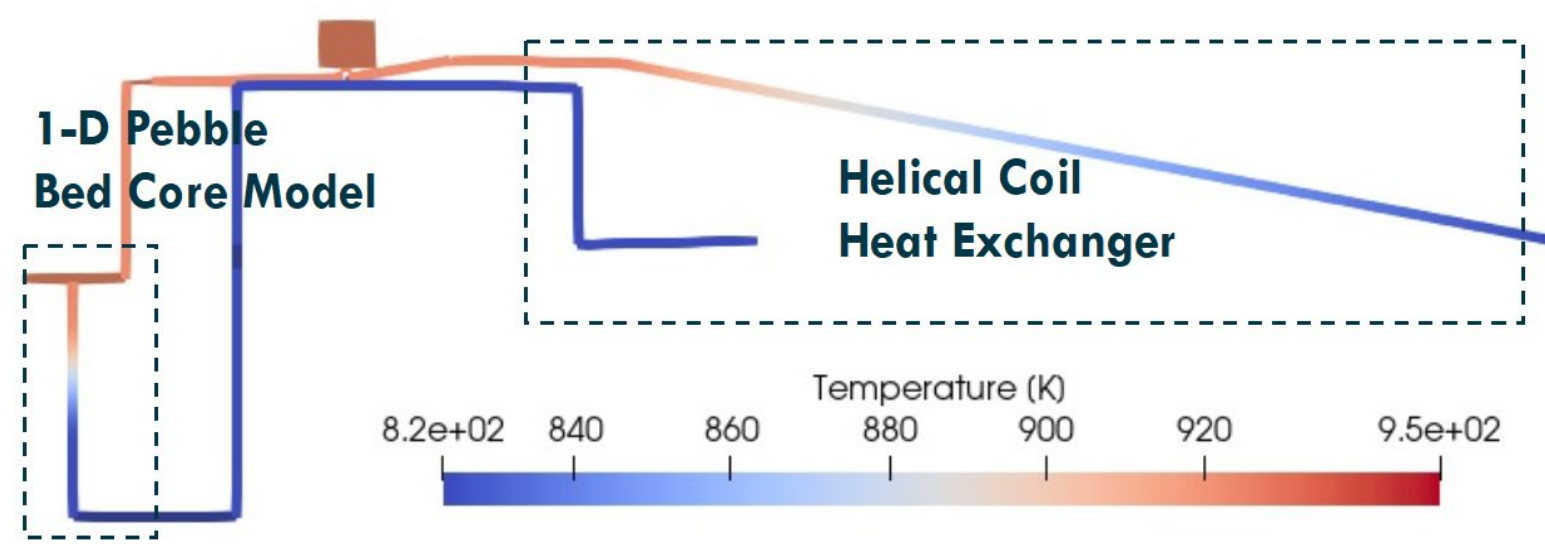

Figure 7. Fluid system temperature distribution inside the FHR balance of plant.

\subsubsection{Near- and Long-Term Capabilities}

Interest in FHR simulations using NEAMS tools has been steadily increasing. A few potential near- and long-term up-and-coming capabilities that are expected as summarized below.

- Near Term:

- Coupled SAM+Pronghorn transient FHR model

- Nek simulation of the core and pebble-reflector interface to obtain closure relations for Pronghorn.

- Long Term:

- Coupled Griffin+Pronghorn+SAM transient multiphysics simulation

- 3-D multiphysics transient simulations of FHR model

- Deriving closure relations in Nek to feed into Pronghorn analysis.

\subsection{Molten Salt Reactors (MSR)}

Similar to HTGRs, MSR come in a variety of design variants. The two main groups can be summarized as thermal designs (usually with fluoride salts and graphite moderator channels), or fast designs (typically open-pool-type with chloride salts). The main distinction between MSR and FHR is that the fuel is dissolved entirely in solution. This leads to novel challenges not typically encountered in other reactor types (i.e., the advection of delayed neutron precursors out of the active core region). These and other considerations must be accounted for. The open-source Molten Salt Fast Reactor (MSFR) is primarily showcased in the VTB repository. Additional MSR types are expected to be included in the near and long term to provide a comprehensive list of example simulations. The MSFR is a $3 \mathrm{GW}$ design with fuel dissolved in LiF carrier salt [14][15]. Simulations using Griffin coupled with Pronghorn (both in steady and transient conditions) are included in the VTB repository, along with a high-fidelity Nek analysis. 


\subsubsection{Current Capabilities}

Similarly, to the previous cases, Griffin is used to compute the neutron flux and power distribution in the reactor that it then transfers to Pronghorn to estimate the temperature distribution and velocity fields (Figure 8 ). The velocity field can then be leveraged in the transport of delayed neutron precursors, as shown in Figure 9 as part of a novel capability within MOOSE. This allows to compute the effective delayed neutron fraction accounting for delayed neutrons being emitted outside of the active core region. The simulation leverages simplified models to account for turbulent flow mixing effects.
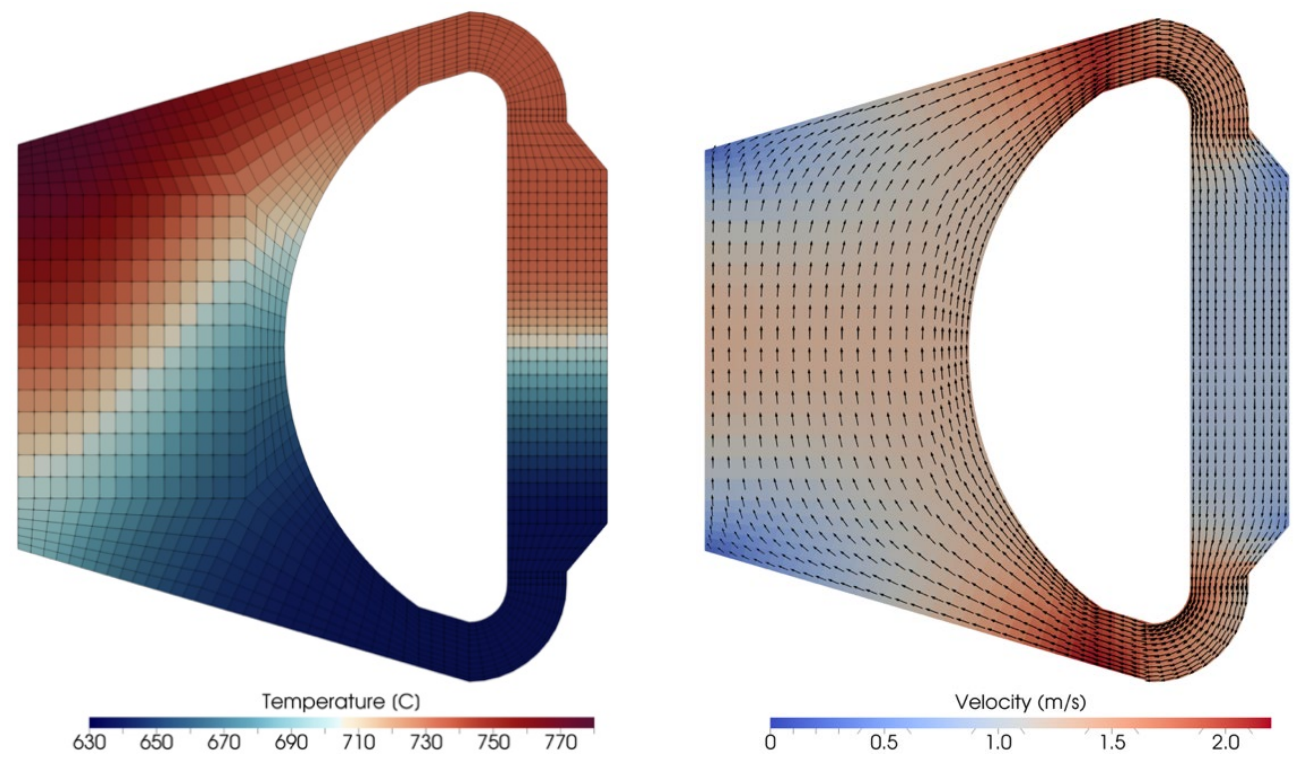

Figure 8. Coupled Griffin+Pronghorn simulation of the MSFR.

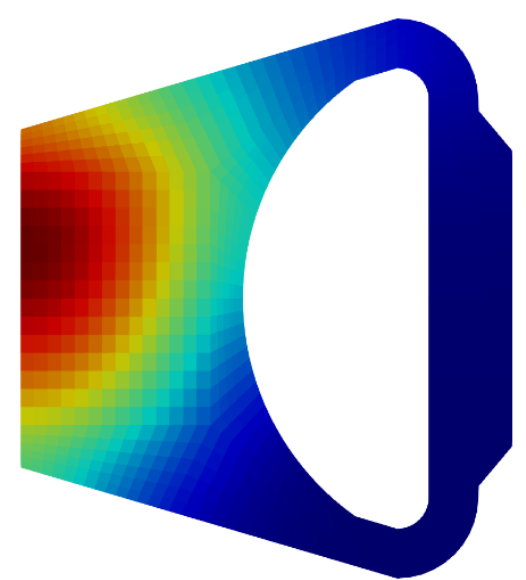

DNP Group 6

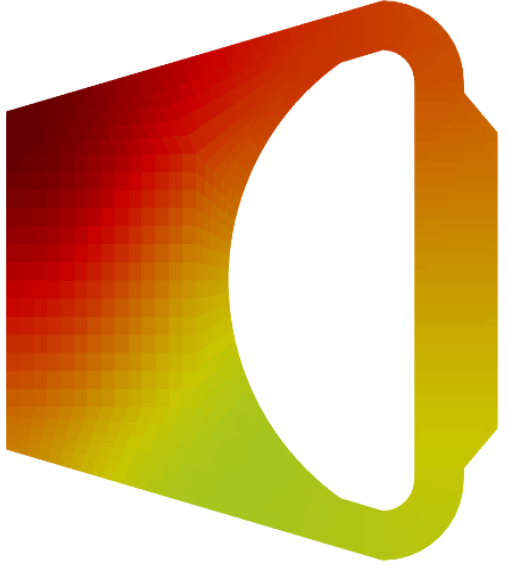

DNP Group 3

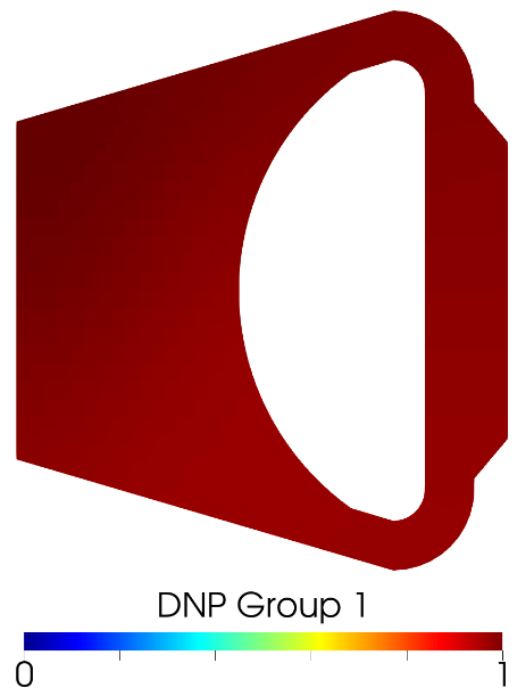

0

Figure 9. Illustration of the recently implemented MSR delayed neutron drifting effect using Griffin+Pronghorn. 
Preliminary transient Griffin+Pronghorn simulations were also added to the VTB. The example is for an unprotected loss-of-flow event. The pumping force is assumed to be reduced by half, no control rods are inserted, and the heat exchanger still acts as a heat sink. The simulation is initialized using the steady-state conditions.

A higher-fidelity Nek model of the MSFR core is also included in the VTB repository. The RANS model was used to resolve the flow inside the geometry, with incompressible flow assumptions. The resulting steady-state solution of the velocity field is shown in Figure 10. The results compare reasonably well with the Pronghorn model in Figure 8 and are expected to be improved upon in the future. In the long run, Nek results are expected to form the basis of closure relations in Pronghorn coarse-mesh models of these reactor types.

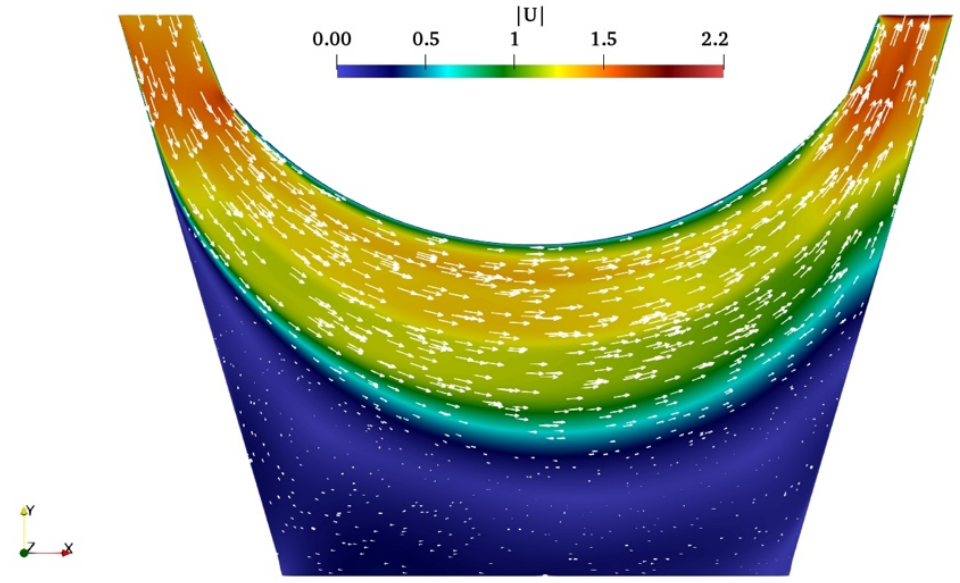

Figure 10. High-fidelity Nek-5000 simulation of the MSFR core.

\subsubsection{Near- and Long-Term Capabilities}

Near/long-term upcoming capabilities in terms of NEAMS modeling of MSR concepts are summarized below.

- Near Term:

- Improved turbulence treatment of MSFR models in Pronghorn

- Leveraging Nek results for closure relations in Pronghorn

- SAM primary system model of the MSFR

- SAM primary system model of the thermal spectrum Molten Salt Reactor Experiment (MSRE).

- Long Term:

- Coupled Griffin+Pronghorn+SAM transient multiphysics simulation of the MSFR

- 3-D multiphysics transient simulations of MSFR model

- Griffin+SAM transient multiphysics simulation of the MSRE

- Thermal property perturbation propagation to accident scenarios

- Species tracking in the system (off-gas versus in-solution versus precipitating). 


\subsection{Sodium Fast Reactors (SFR)}

SFRs are a well-establish class of advanced reactors that operate in the fast spectrum and rely on $\mathrm{Na}$ (or $\mathrm{NaK}$ ) as a coolant. The fuel is typically in oxide or metallic form, and the primary system is either in a pool or a loop layout. The initial example of the VTB consists of a 3D single assembly calculation that couples Griffin, SAM, BISON, and a MOOSE tensor mechanics model together. The main objective of this multiphysics model is to demonstrate that this MOOSE-based model can explicitly capture the feedback mechanisms that dominate SFR behavior.

\subsubsection{Current Capabilities}

For the neutronics model, a single homogeneous 3D hexagonal assembly consisting of an active fuel region surrounded by a bottom and top axial reflector region is modeled, with reflective boundary conditions on the radial directions to mimic an infinite domain, while void boundary conditions are applied axially. The assembly power is set to a value representative of a small SFR core. A representative 2D axisymmetric fuel rod is modeled with BISON where the power density generated by Griffin is normalized to correspond to the average pin power. BISON provides both the fuel temperature and the axial expansion feedbacks to the neutronics model. The coolant channel is modeled via a ID model in SAM, which is taking the wall temperature profile from BISON and provides the corresponding coolant temperature rise based on user-imposed mass flow rate and outlet pressure. Finally, a simple 2D core support plate model relying on the MOOSE tensor mechanics model provides the radial expansion feedback corresponding to the inlet temperature. This example provides all the functionalities required for scaling up to a full-core SFR model for both steady-state and transient conditions. The coupling scheme workflow is showcased in Figure 11.

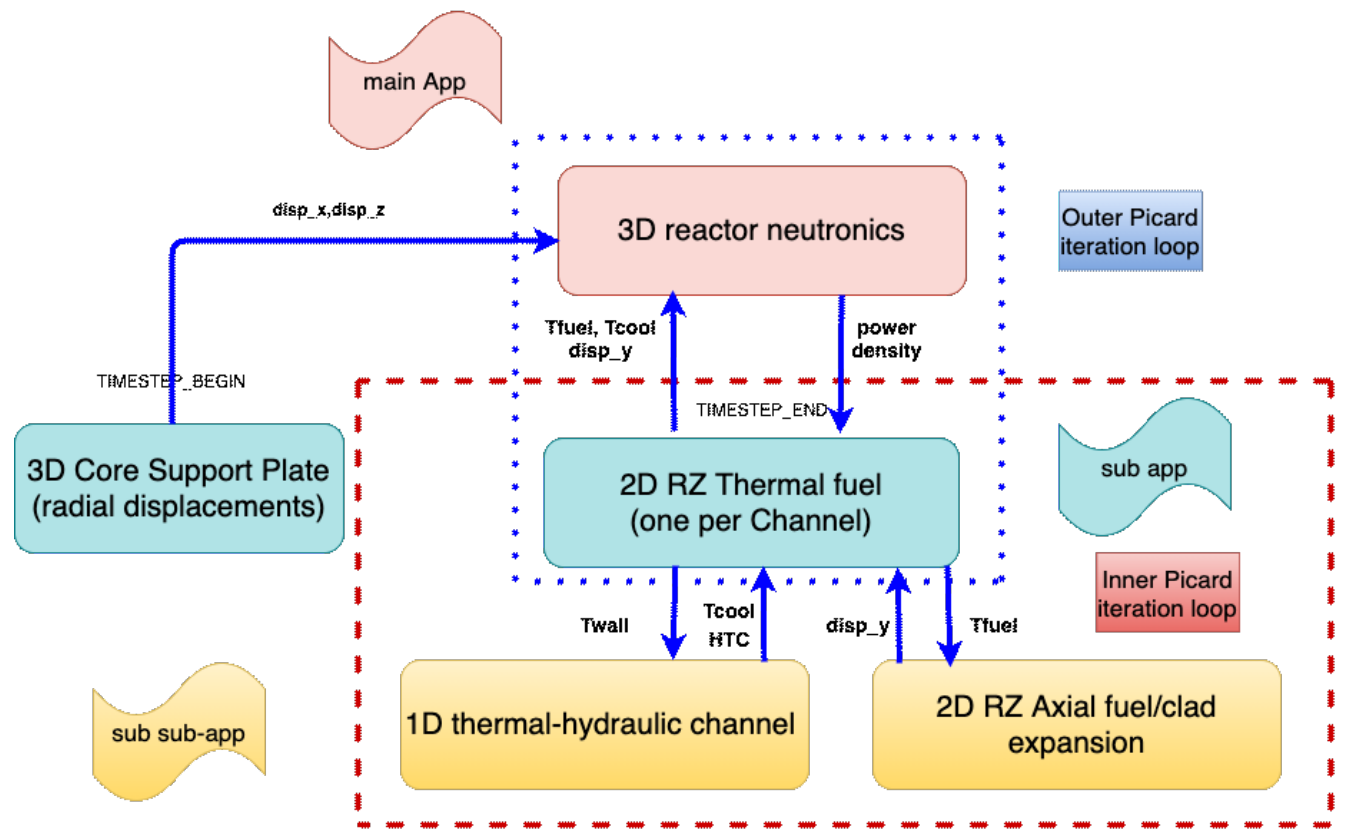

Figure 11. Coupling scheme for SFR analysis. 
An illustration of the different meshes used by each of the three main blocks is shown in Figure 12. This illustrates the flexibility of leveraging MOOSE-based tools and coupling together different domain spaces. The 3D Griffin model computes the power distribution while accounting for the fuel and coolant temperature feedback as well as the radial and axial mechanical deformation feedbacks, which are primordial in SFR modeling. In the future, the Griffin core model can be scaled up to cover the full-core region. The BISON and SAM models would remain similar, with one instance per fuel location populated by the MultiApps system. Also, the core support plate can be coupled with a primary loop model to account for thermal expansion changes due to variations in inlet temperature.

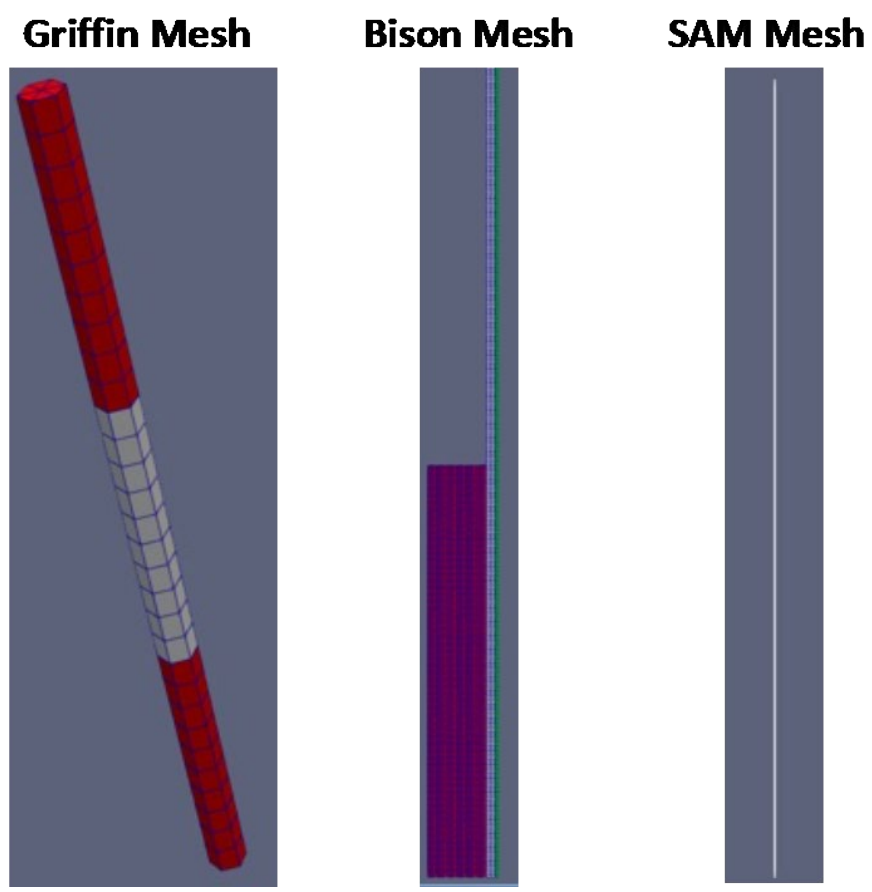

Figure 12. Different meshes used in each code block of the SFR lattice example. 

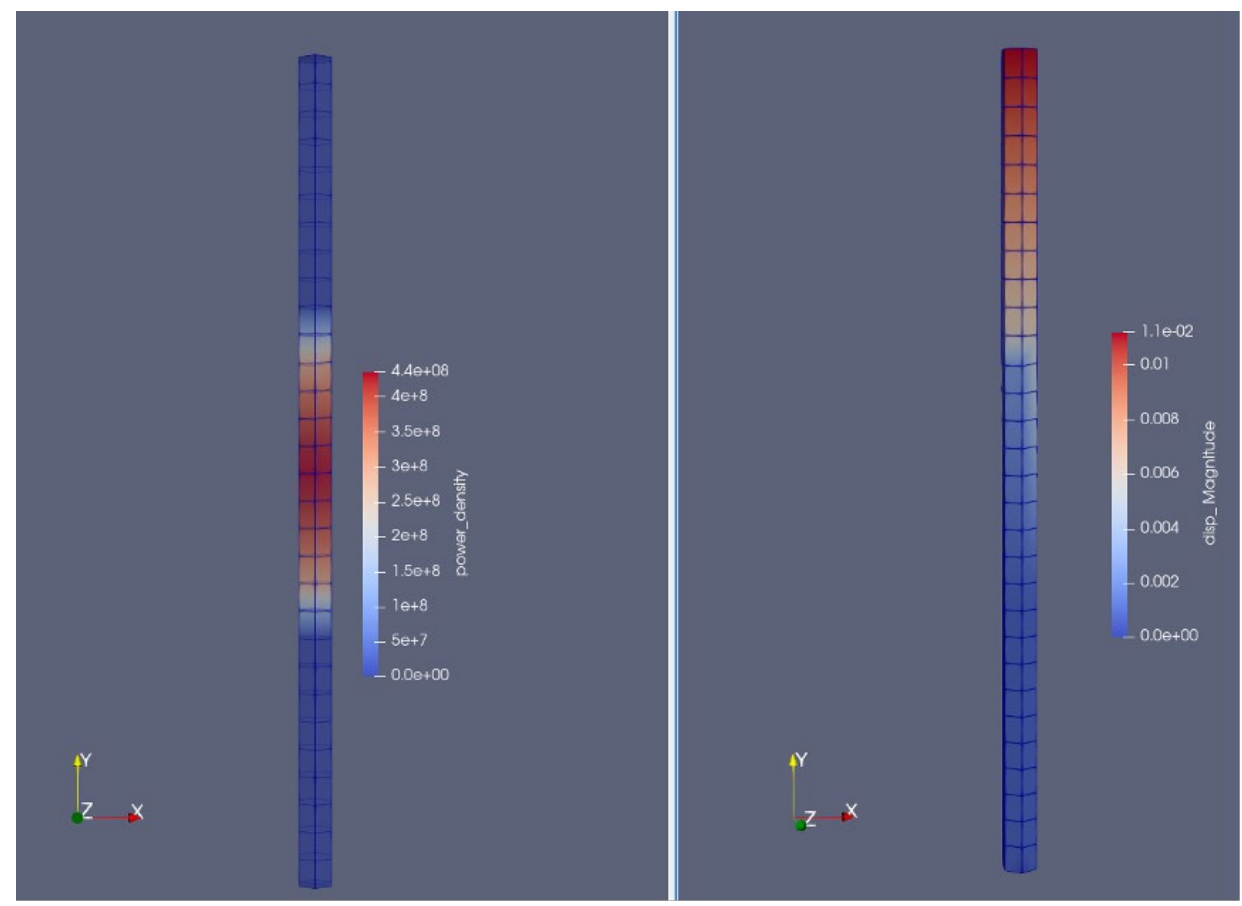

Figure 13. Power density and axial displacement magnitude.

\subsubsection{Near- and Long-Term Capabilities}

Ongoing activities in modeling of SFR reactors using NEAMS tools are expected to be included in the VTB repository in the near term. Some additional capabilities are expected to come available in the longer term.

- Near Term:

- Additional multiphysics transient examples using SFR lattice example case.

- Long Term:

- Pronghorn-based subchannel solver to resolve flow within assemblies

- Core-section 3D multiphysics transient simulation of core bowing effect

- SAM primary system loop transient model.

\subsection{Heat-Pipe Microreactor (HP-MR)}

A wide range of microreactor concepts are being pursued in the nuclear community. They can be mainly grouped between the heat-pipe and gas-cooled variety as previously explained. This section will primarily focus on the HP-MR variants as the gas-cooled ones are relatively similar to HTGR concepts and are planned on being further investigated in the long term. A 2-MW concept developed as modeling exercise [16]. by the NEAMS program is showcased in the VTB repository. It leverages TRISO fuel particles contained within a core block and rotating control drums within the radial reflector. The core is subdivided into 30 fuel assemblies in the shape of a graphite monolith containing slotted fuel pellets, $\mathrm{YH}_{2}$ moderating material, and heat pipes. The initial model hosted on the repository consists of a coupled Sockeye-BISON simulation. 


\subsubsection{Current Capabilities}

A simplified $1 / 6$ core of the HP-MR was generated for preliminary assessment. The current model assumes a constant power distribution within the core (this will be updated later with a Griffin-generated power density). This is leveraged by the heat conduction module in MOOSE and BISON to estimate the resulting surface temperature and conditions within the monolithic block. Sockeye is then used for steady-state heat removal using the equivalent thermal conductivity model. The computation scheme is illustrated in Figure 14.

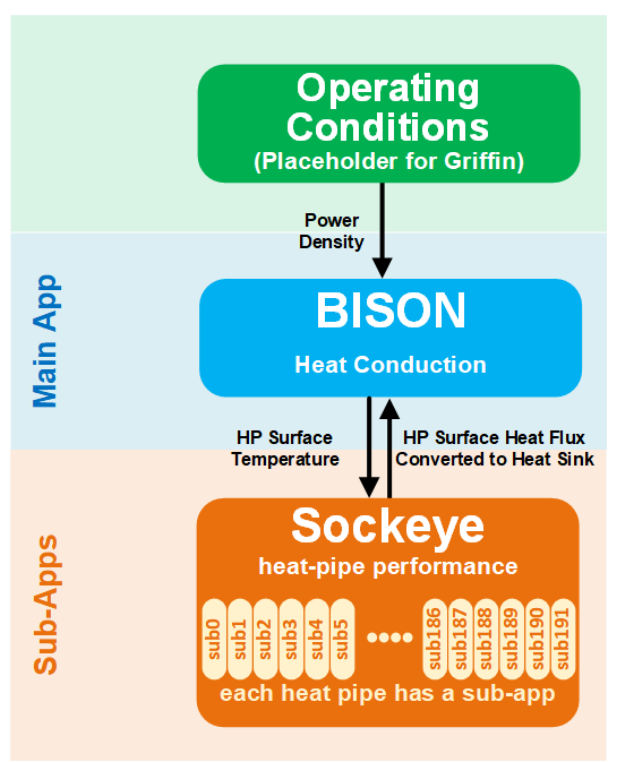

Figure 14. Coupled Griffin+Pronghorn results for the HP-MR analysis

A rendering of the model geometry is shown in Figure 15. A multiphysics steady-state analysis is conducted in the full-core model by coupling the BISON thermo-mechanical solver to the Sockeye heat-pipe thermal performance solver. Figure 16 displays the temperature throughout the core at steady-state. 


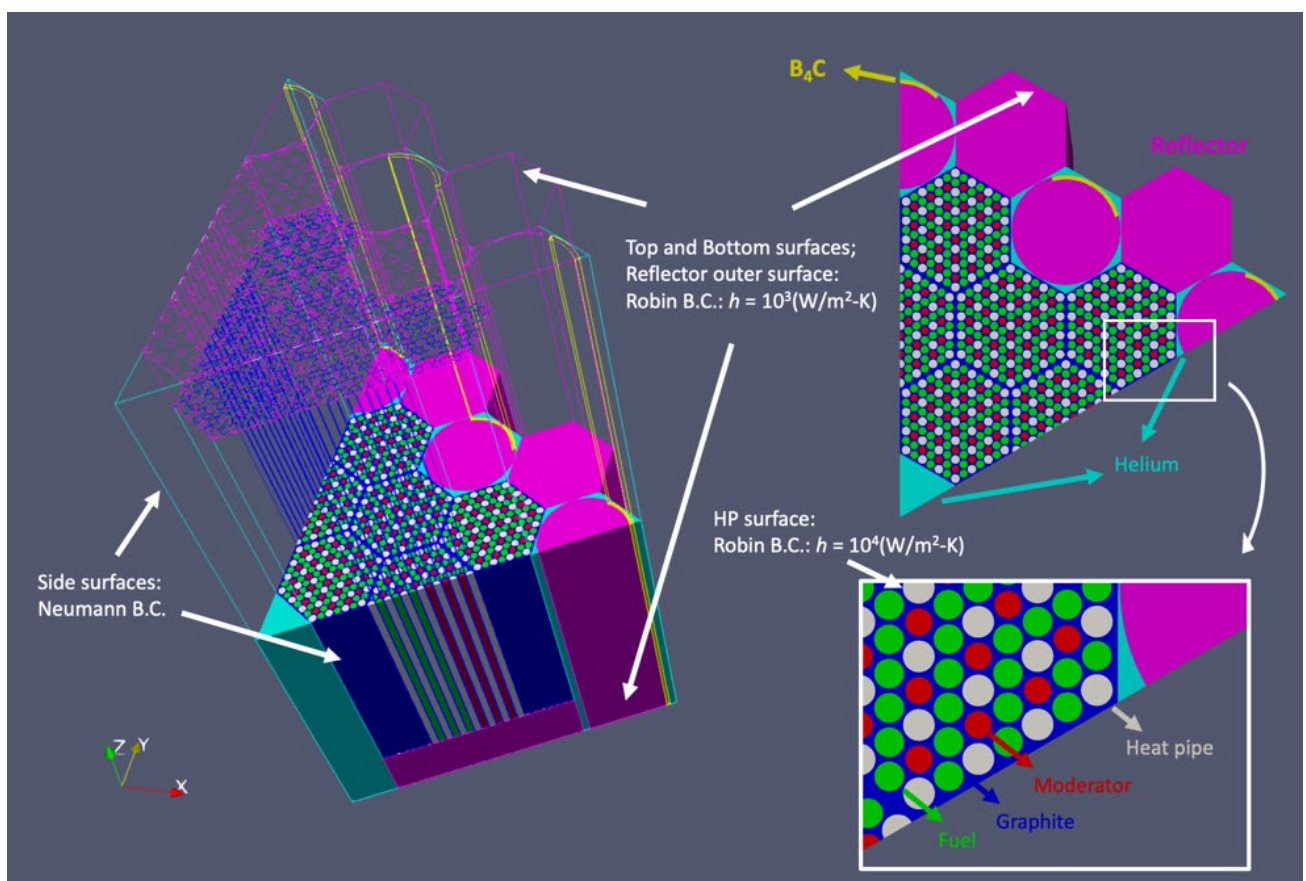

Figure 15. Overview of the HP-MR model.

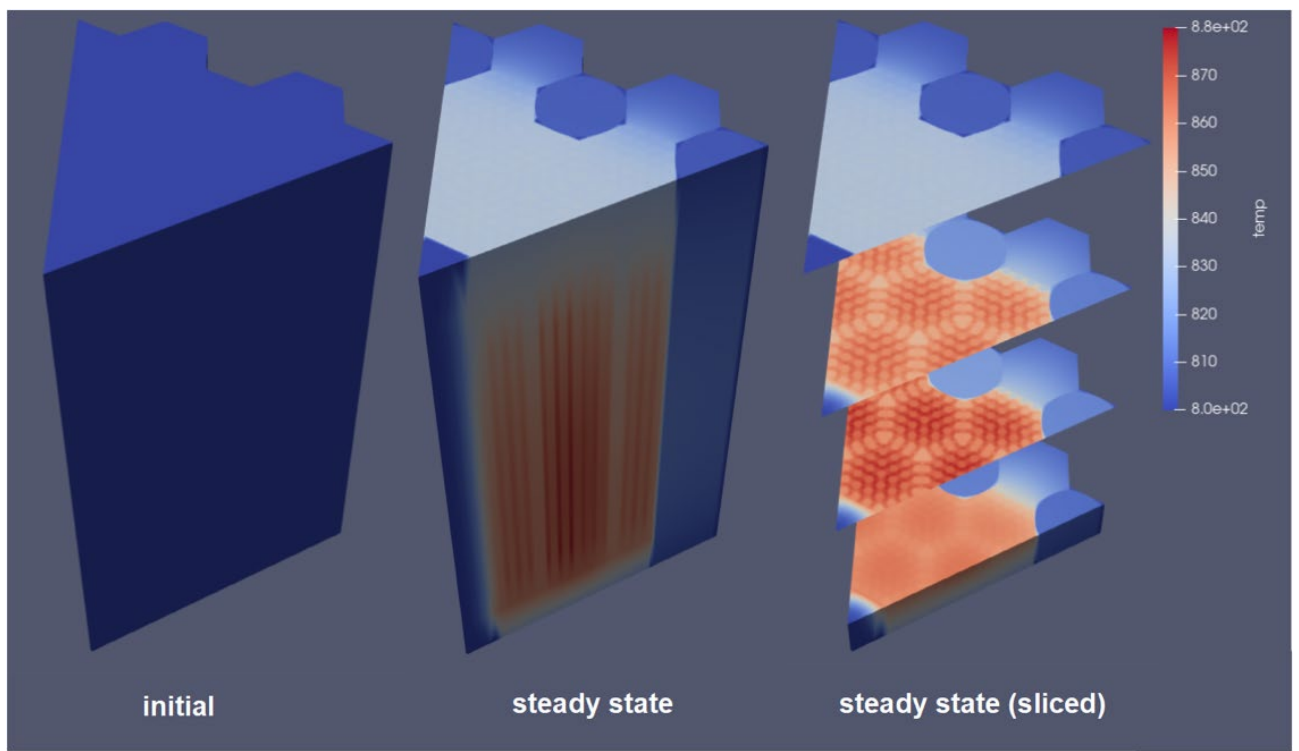

Figure 16. Results from the multiphysics simulation of the HP-MR. Temperature values are in K. 


\subsubsection{Near- and Long-Term Capabilities}

Upcoming M\&S capability for the HP-MR concept are summarized below.

- Near Term:

- Including the Griffin neutronics block to resolve the neutron transport equation and provide power distribution within the $1 / 6$ core model.

- Long Term:

- Coupled load-following and decay heat removal transient simulations of the HP-MR model.

- Single and multiple heat-pipe failure analysis using coupled multiphysics.

\section{REFERENCES}

[1] Permann, Cody J., et al. "MOOSE: Enabling massively parallel multiphysics simulation." SoftwareX 11 (2020): 100430.

[2] Wang, Yaqi, Sebastian Schunert, and Vincent Laboure. Rattlesnake Theory Manual. INL/EXT-17-42103. Idaho National Laboratory, Idaho Falls, Idaho (United States), 2018.

[3] Shemon, Emily R., Micheal A. Smith, and Changho Lee. Proteus-SN User Manual. ANL/NE-1 4/6 (Rev 3.0). Argonne National Laboratory, Lemont, Illinois (United States), 2016.

[4] Novak, A. J., Carlsen, R. W., Schunert, S., Balestra, P., Reger, D., Slaybaugh, R. N., and Martineau, R. C. "Pronghorn: A Multidimensional Coarse Mesh Application for Advanced Reactor Thermal-Hydraulics." Nuclear Technology. (2021): 1-26 https://doi.org/10.1080/00295450.2020.1825307.

[5] Schunert, Sebastian, et al. "Coupling of Pronghorn and RELAP-7 for a Pebble Bed Reactor." INL/CON-19-54415-Rev000. Idaho National Laboratory, Idaho Falls, Idaho (United States), 2020.

[6] Hu, Rui, et al. SAM User's Guide. ANL/NSE-19/18 Rev. 1. Argonne National Laboratory, Lemont, Illinois (United States), 2021.

[7] Merzari, Elia, et al. "Toward exascale: overview of large eddy simulations and direct numerical simulations of nuclear reactor flows with the spectral element method in Nek5000." Nuclear Technology 206.9 (2020): 1308-1324. https://doi.org/10.1080/00295450.2020.1748557.

[8] Williamson, Richard L., et al. "BISON: A flexible code for advanced simulation of the performance of multiple nuclear fuel forms." Nuclear Technology (2021): 1-27.

[9] Hansel, Joshua E., et al. "Sockeye: A One-Dimensional, Two-Phase, Compressible Flow Heat Pipe Application." Nuclear Technology (2021): 1-22. https://doi.org/10.1080/00295450.2020.1861879.

[10] GA. General Atomics' Prismatic Modular High Temperature Gas Cooled Reactor. Technical Report, General Atomics, 2014.

[1 1] Rui Hu. SAM Theory Manual. ANL/NE-17/4, Argonne National Laboratory, Lemont, Illinois, 2017. 
[12] Prasad Vegendla, Rui Hu, and Ling Zou. Multi-Scale Modeling of Thermal-Fluid Phenomena Related to Loss of Forced Circulation Transient in HTGRs. ANL-19/35, Argonne National Laboratory, Lemont, Illinois, 2019.

[13] Balestra, Paolo, et al. "PBMR-400 benchmark solution of exercise 1 and 2 using the moose based applications: MAMMOTH, Pronghorn." EPJ Web of Conferences. Vol. 247. EDP Sciences, 2021.

[14] H. Rouch, O. Geoffroy, et al. "Preliminary thermal-hydraulic core design of the molten salt fast reactor (msfr)." Annals of Nuclear Energy, 64:449-456, 2014. doi:10.1016/i.anucene.2013.09.012.

[15] Brovchenko, Mariya et al. Neutronic benchmark of the molten salt fast reactor in the frame of the evol and mars collaborative projects. EPJ Nuclear Sci. Technol., 5:2, 2019. doi:10.1051/epin/2018052.

[16] Nicolas E. Stauff, Kun Mo, Yan Cao, Justin W. Thomas, Yinbin Miao, Changho Lee, Christopher Matthews, Bo Feng, "Preliminary Applications of NEAMS Codes for Multiphysics Modeling of a Heat Pipe Microreactor," proceedings of ANS Annual 2021 Meeting, June (2021). 